University of South Florida

DIGITAL COMMONS

Digital Commons @ University of

@ UNIVERSITY OF SOUTH FLORIDA

South Florida

Marine Science Faculty Publications

College of Marine Science

$11-15-1998$

\title{
Detection of the Fast Kelvin Wave Teleconnection Due to El Niño-Southern Oscillation
}

\author{
Steven D. Meyers \\ Florida State University, smeyers@usf.edu \\ Arne Melsom \\ Norwegian Meteorological Institute \\ Gary T. Mitchum \\ University of South Florida, mitchum@usf.edu \\ James J. O'Brien \\ University of South Florida
}

Follow this and additional works at: https://digitalcommons.usf.edu/msc_facpub

Part of the Marine Biology Commons

\section{Scholar Commons Citation}

Meyers, Steven D.; Melsom, Arne; Mitchum, Gary T.; and O'Brien, James J., "Detection of the Fast Kelvin Wave Teleconnection Due to El Niño-Southern Oscillation" (1998). Marine Science Faculty Publications. 46.

https://digitalcommons.usf.edu/msc_facpub/46

This Article is brought to you for free and open access by the College of Marine Science at Digital Commons @ University of South Florida. It has been accepted for inclusion in Marine Science Faculty Publications by an authorized administrator of Digital Commons @ University of South Florida. For more information, please contact digitalcommons@usf.edu. 


\title{
Detection of the fast Kelvin Wave teleconnection due to El Niño-Southern Oscillation
}

\author{
Steven D. Meyers, ${ }^{1,2}$ Arne Melsom, ${ }^{3}$ Gary T. Mitchum, ${ }^{4}$ and James J. O'Brien ${ }^{1}$
}

\begin{abstract}
Previous analyses of the ocean state along the western American coast have often indicated unexpectedly slow and limited propagation of coastally trapped Kelvin waves associated with the El Niño-Southern Oscillation. In contrast, theoretical and numerical ocean models demonstrate that these Kelvin waves are a rapid and long-range teleconnection between the low- and high-latitude Pacific Ocean, strongly impacting both the surface coastal currents and nutrient upwelling. Sea level variations along the western coast of North America are reexamined under the assumption that tropically forced Kelvin waves are produced in bursts of several months duration. A cross-correlation analysis, restricted to mid-1982 to mid-1983, is performed between Galapagos Island and stations along western Central and North America. A coastally trapped Kelvin wave is revealed to propagate at a speed of $2-3 \mathrm{~m} \mathrm{~s}^{-1}$ from the tropical Pacific to the Aleutian Island Chain. The observed phase speed agrees with the estimated speed of a Kelvin wave based on the average density profile of the ocean near the coast. Weaker El Niño events in 1986/1987 and 1991/1992 appear to contain a combination of this remotè signal and local wind forcing. The wave propagation speed calculated from the spectral phase is shown to be sensitive to the presence of other (noise) processes in the observations. This is demonstrated through an analysis of a synthetic sea level data set that contains many of the essential features of the real sea level data. A relatively small level of red nuise can give a $100 \%$ expected error in the estimated propagation speed. This suggests a new explanation for this important inconsistency within dynamical oceanography.
\end{abstract}

\section{Introduction}

The El Niño-Southern Oscillation (ENSO) alters the upwelling along the west coast of North America. These changes are, in part, produced by an extension of the oceanic mechanism underlying ENSO, namely, a large-scale equatorial Kelvin wave [Wyrtki, 1974; Busalacchi and O'Brien, 1981]. When this wave crosses the tropical Pacific and arrives at the South American coast, its energy splits: a portion reflects as a westward moving Rossby wave, and the remaining energy travels toward each pole as coastal Kelvin waves [Clarke, 1983]. Coastally trapped Kelvin waves are solutions of well-known mathematical equations describing ocean circulation [Moore, 1968]. Their analytical form is almost identical to the equatorial variety, a nondispersive, rapid $\left(2-3 \mathrm{~m} \mathrm{~s}^{-1}\right)$, gravity wave.

Upwelling brings deep, nutrient-rich waters to the surface, where they feed a strong biological cycle, including commercial fisheries. Kelvin waves associated with warm events of ENSO depress the thermocline and suppress upwelling, while those associated with cold events raise the thermocline, enhancing upwelling. Interannual changes in coastal upwelling were tied by Ware and Thomson [1991] to variations in the population

\footnotetext{
'Center for Ocean-Atmospheric Prediction Studies, Florida State University, Tallahassee.

${ }^{2}$ Now at Department of Marine Science, University of South Florida, St. Petersburg.

${ }^{3}$ Norwegian Meteorological Institute, Oslo.

${ }^{4}$ Department of Marine Science, University of South Florida, St Petersburg.

Copyright 1998 by the American Geophysical Union.

Paper number $98 \mathrm{JC} 02402$.

0148-0227/98/98JC-02402\$09.00
}

and health of several species of fish. J. Norton (unpublished manuscript, 1998) showed that year-to-year survivability of rockfish off the western United States is strongly influenced by ENSO.

Equatorial Kelvin waves are driven by westerly wind bursts in the western tropical Pacific [Kessler et al., 1995]. The coastal extension of these waves should therefore propagate in a series of intraseasonal events lasting a total of $\leq 1$ year. They are generated intermittently on an interannual basis during ENSO extremes, giving the long-term sea level (SL) record a broad spectral structure. (The waves lose their low-frequency energy along the continental boundary by generating midlatitude Rossby waves [Johnson and O'Brien, 1990; McCalpin, 1995]. Thus they undergo a high-pass filtering as they progress poleward.)

Numerical ocean models show that tropically forced Kelvin waves are a significant source of interannual variability of the nearshore ocean circulation along western America [Hurlburt et al., 1976; McCreary, 1976; Pares-Sierra and O'Brien, 1989], as well as the generators of large-amplitude Rossby waves in the midlatitude Pacific basin [Johnson and O'Brien, 1990; Jacobs et al., 1994], which play a vital role in decadal climate variability [Meyers et al., 1996].

However, several studies of ocean data have yielded ambiguous results concerning the existence of this form of poleward propagating wave. Enfield and Allen [1980] examined measurements of monthly sea level anomalies (SLA) along the western coast of North America using both correlation and spectral techniques. Their correlation study indicated propagation from the tropics to the high latitudes of the northeast Pacific Ocean (NEP) into the Gulf of Alaska (GOA) at speeds of roughly $2.1 \mathrm{~m} \mathrm{~s}^{-1}$. A narrow band-pass filter of the SL data in 


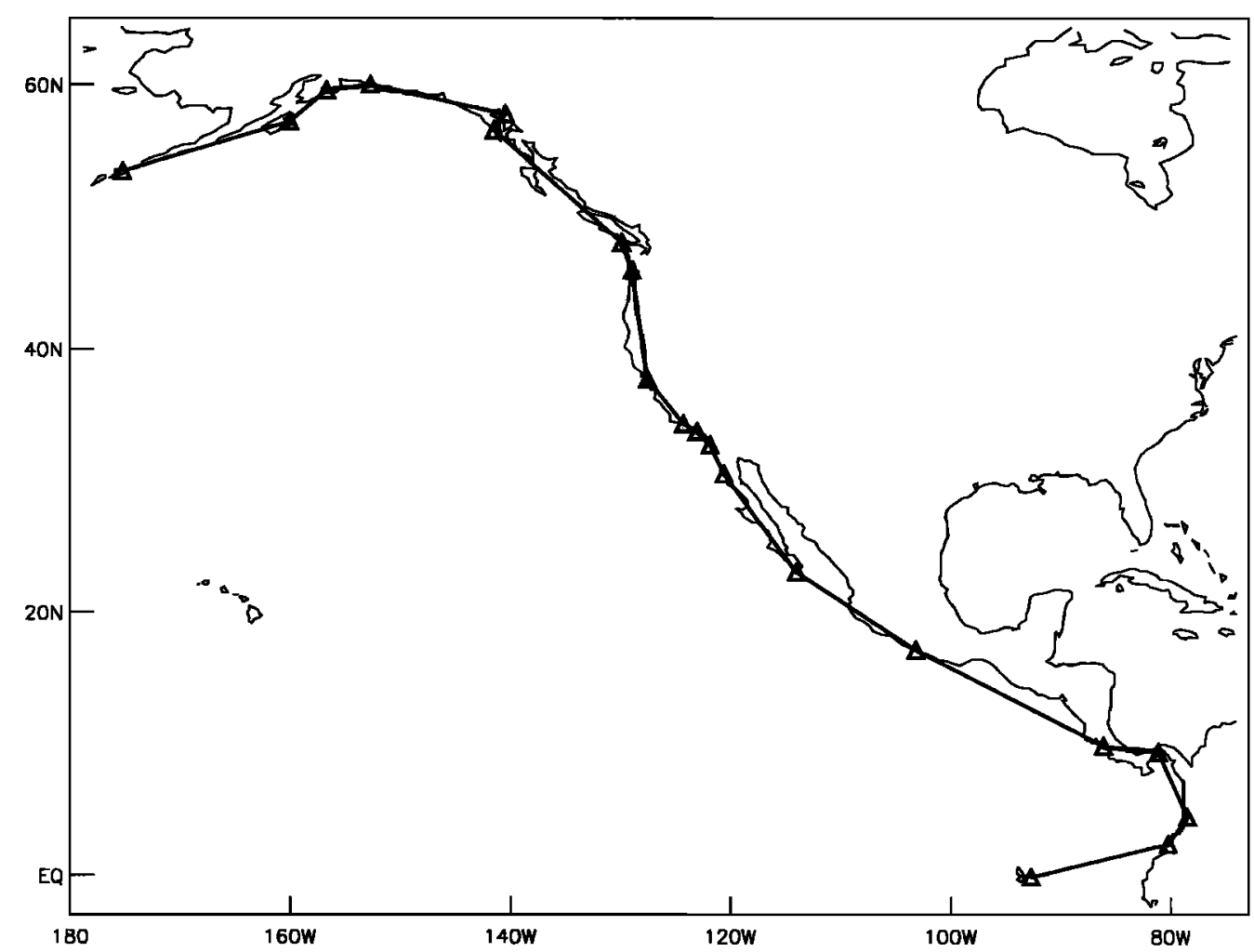

Figure 1. The stations from which daily sea level observations were obtained (triangles), connected by lines that show roughly the travel path of the Kelvin wave. Information regarding each station is provided in Table 1.

the range 2-5 years (roughly corresponding to ENSO) indicated a propagation speed of $\sim 0.9 \mathrm{~m} \mathrm{~s}^{-1}$, based on the average phase difference between stations. Chelton and Davis [1982] also studied monthly SLAs at these interannual frequencies and found a relatively slow propagation, about $40 \mathrm{~cm} \mathrm{~s}^{-1}$, from the tropics into the GOA. Fast coastal waves $\left(2-4 \mathrm{~m} \mathrm{~s}^{-1}\right)$ have been found in the NEP at subannual frequencies [Christensen et al., 1983; Spillane et al., 1987; Enfield, 1987]. The subannual waves were presumed unrelated to ENSO, which occurs at interannual periods. Norton and McLain [1994] showed the propagation of temperature anomalies from the tropics along the coast of California over a wide range of speeds. These model and observational studies present an inconsistency within oceanography which questions our understanding of basic ocean dynamics.

Daily SL measurements in the eastern Pacific (Figure 1) are examined under the assumption that these large Kelvin waves occur in short-duration events, lasting several months to 1 year. Section 2 describes the data and calculation of the SLA. Section 3 presents the results of the lag-correlation analysis for 1982/1983, which shows a signal resembling a coastally trapped Kelvin wave propagating from the tropical Pacific to the GOA. The correlation values attain the $95 \%$ significance level, and the correlation patterns match a calculated propagation of a Kelvin wave based on climatological Levitus [Levitus and Boyer, 1994] density profiles near the coast. Similar analyses of later years reveals qualitative differences between ENSO events. These results are compared with those from an artificial data set, which demonstrates that processes not necessarily related to ENSO might alter the propagation speed estimated using spectral filtering techniques. Section 4 discusses the results.

\section{Data}

\subsection{Tide Gauge}

Sea level measurements were obtained from the Sea Level Center, University of Hawaii (UH), and the National Ocean Service (NOS) from stations along the western coast of North America (Figure 1). The daily time series of sea level (available over the World Wide Web (WWW)) from UH were obtained with the tidal signals removed. For the hourly NOS time series it was necessary to remove the tides and compute daily averages.

Small gaps in the records are filled using cubic splines. For each station a daily climatology is then computed based on the entire record. The daily climatology is first smoothed with Hanning filters and then subtracted from the splined daily values to obtain the SLAs, which are smoothed with 10 forward and backward 1-2-1 Hanning filters.

\subsection{Density Profiles}

Vertical density profiles are obtained from the Levitus atlas [Levitus and Boyer, 1994]. The data are compilations of measurements [Levitus and Gelfeld, 1992] from 1900-1992. In addition, data gathered as a result of the National Oceanographic Data Center (NODC) National Oceanographic Data Archaeology and Rescue (NODAR) and the Global Oceanographic Data Archaeology and Rescue (GODAR) projects were included [Levitus et al., 1994]. These data are available from the NODC on a $1^{\circ} \times 1^{\circ}$ grid at 30 selected depths from the sea surface to $5500 \mathrm{~m}$ depth and were obtained via the WWW.

\subsection{Synthetic Sea Level}

An artificial time series is created in order to examine the spectral representation of ENSO-dominated sea level mea- 

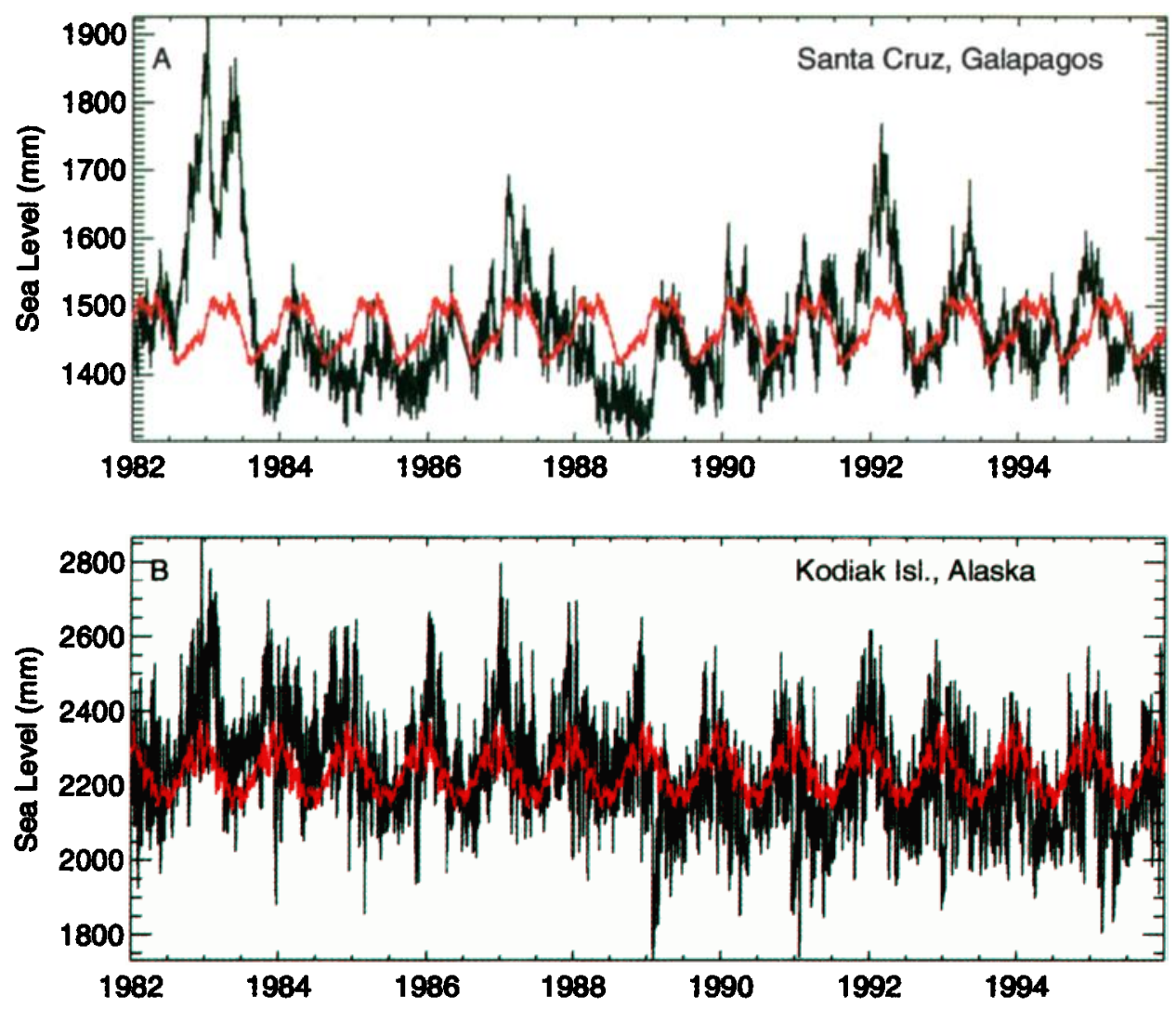

Plate 1. The 1982-1995 daily sea level (black) at (a) Galapagos Islands, Ecuador, and (b) Kodiak Island; Alaska. The daily climatology, shown in red, has been smoothed.

surements. A propagating series of Gaussian $\left[\exp (-t / T)^{2}\right]$ pulses with a period of 4 years and duration $T=6$ months are sampled daily using a collection of $(N=10)$ equidistant stations. The speed of propagation between stations is $200 \mathrm{~km}$ $\mathrm{d}^{-1}$. This mimics several of the key characteristics of the sea level anomalies described below.

An autoregressive function, $y_{t+1}^{\prime}=\beta\left(\alpha y_{t}^{\prime}+W_{t}\right)$, where $\beta$ Is a scaling parameter, $i=1, \cdots, N$ is the station index, and $W^{l}$ is a white noise process with unit variance, is added to the synthetic signal at each station. The regression coefficient, $\alpha=0.9$, is the lag- 1 autocorrelation of the daily sea level at Galapagos Island.

\section{Results}

\subsection{SL Anomalies}

Tropical SL variations contain a relatively large interannual signal corresponding to ENSO, whereas higher-latitude stations are more strongly influenced by the annual cycle (Plate 1). Both the tropical and high-latitude SLA show a large anomaly early in 1983 (Figure 2). At the tropical stations a second peak follows several months later. The first peak is associated with the first baroclinic mode; the second peak may be related to the second or higher baroclinic modes [Lukas et al., 1984]. The scale width of the peaks is about 4 months, but the total duration of the $1982 / 1983$ positive anomaly is about 12 months. The first peak contains an increase of roughly $40 \mathrm{~cm}$ in less than 6 months, and the decline is at a similar rate. The SL variations associated with ENSO are abrupt, impulse-like events and therefore cannot be represented in a narrow spec- tral band, which would be equivalent to assuming the signal is made of only a few (or one) sinusoidal functions.

El Niño events are also seen in the tropical record during 1986/1987, 1991/1992 and, weakly, in 1993 and 1994. Positive anomalies are seen at the higher-latitude stations during the same years. The identification of anomalies at Kodiak Island is complicated by a shift in the mean SL around 1989. However, the 1992 anomaly remains clear, but the 1993 and 1994 anomalies are almost indistinguishable. The Kodiak observations possess additional peaks that do not correspond to ENSO events (e.g., the beginning of 1986).

\subsection{Lag Correlations}

The propagation speed of a first baroclinic mode Kelvin wave $c$ is controlled by the vertical density profile of the ocean, $\rho(z)$, as $c=\left(g H \rho^{-1} \Delta \rho\right)^{1 / 2}$, where $H$ is the depth of the pycnocline (or thermocline), $g$ is the gravitational acceleration $\left(9.8 \mathrm{~m} \mathrm{~s}^{-2}\right), \Delta \rho$ is the density contrast above and below the pycnocline, and $\rho$ is the density below the pycnocline. This relation is used to estimate $c$ along the path of the Kelvin wave as follows. The density profile $\rho(z)$ is obtained from the Levitus atlas [Levitus and Boyer, 1994]. A constant-density surface is selected to represent the pycnocline along the coast (Figure 3 ). The depth of the isopycnal and the mean density above and below (to depths of $2000 \mathrm{~m}$ ) the isopycnal are obtained. The estimated speeds along the coast are then integrated over several weeks to estimate the location of the Kelvin wave as a function of time. The curves in Plate 2 represent this calculated position for two different choices of pycnocline based on the Levitus profiles in Figure 3. 

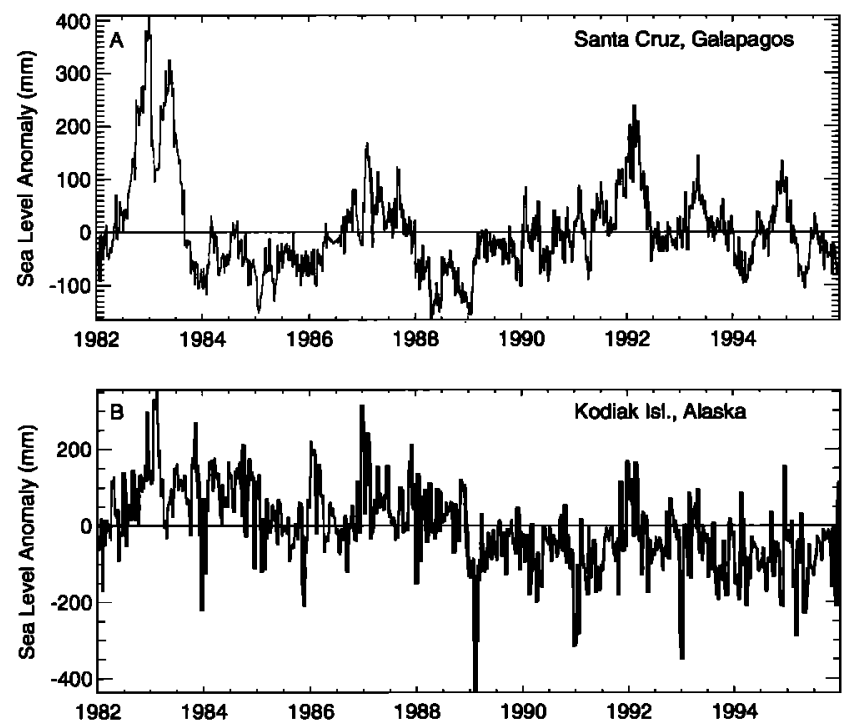

Figure 2. The 1982-1995 sea level anomaly. The daily climatology is removed, highlighting the El Niño-Southern Oscillation (ENSO) signal. (a) Galapagos Islands, Ecuador, and (b) Kodiak Island, Alaska. The El Niño events of 1982/1983, 1986/ 1987, 1991/1992, 1993, and 1994 are revealed, particularly in the tropics. The data have been smoothed with 10 forward and backward 1-2-1 Hanning filters.

To investigate the relation of SLAs in the tropics to those in the NEP, the SL anomaly at each station is lag correlated with the SL anomaly at the Galapagos Islands. Only the measurements from mid-1982 through mid-1983 are used in order to isolate the 1982-1983 warm event. The time lag of maximum correlation and the path distance between the sites yield the speed of propagation (Table 1). A signal appears to travel from the tropics to midlatitudes, past Canada, and at least as far as
Unalaska in the Aleutian Island chain. Propagation in the tropics occurs at speeds somewhat higher than $3 \mathrm{~m} \mathrm{~s}^{-1}$ (Plate 2a). The speed begins to decrease along the Mexican coast and drops to about $2 \mathrm{~m} \mathrm{~s}^{-1}$ in the Gulf of Alaska. The change in speed is due to changes in the vertical structure of the upper ocean with latitude (Figure 3).

An identical correlation analysis of the 1986/1987 warm event (Plate 2) yields features similar to those for the 1982/ 1983 event, but with lower correlations, and the propagation at high latitudes is unclear. An analysis of the 1991/1992 event indicates a northward moving signal originating in the tropics plus a southward moving signal originating in the Gulf of Alaska (Plate 2c). This 1991/1992 pattern was also seen by Ramp et al. [1997]. They performed a study of observational variables from 1991/1992 along the west coast of North America as well as corresponding results from a high-resolution ocean model. They found a fast, intraseasonal Kelvin wave originating in the tropics and a southward, wind-generated signal originating in the GOA.

ENSO-driven Kelvin waves exist for only a few months to 1 year. Correlation analysis during a non-ENSO time period (when no strong Kelvin wave is expected), such as mid-1985 to mid-1986, does not show a propagating feature (Plate 2d) north of southern California. South of this, the correlation pattern matches roughly the theoretical propagation speed and is similar to that found during ENSO extremes. Examination of other non-ENSO time periods shows the same lack of positive correlations north of southern California (not shown). Therefore the strong Kelvin waves exist only for limited periods of time and are correctly thought of as impulse-like events rather than periodic features. Alternatively, a series of impulse-like events possesses a broad spectrum. The lack of an isolated spectral peak for the data in Plate 1 is seen in Figure 4.

To estimate the significance of the correlations, the following method is used. Take two times series $x_{1}(t)$ and $x_{2}(t), t=$
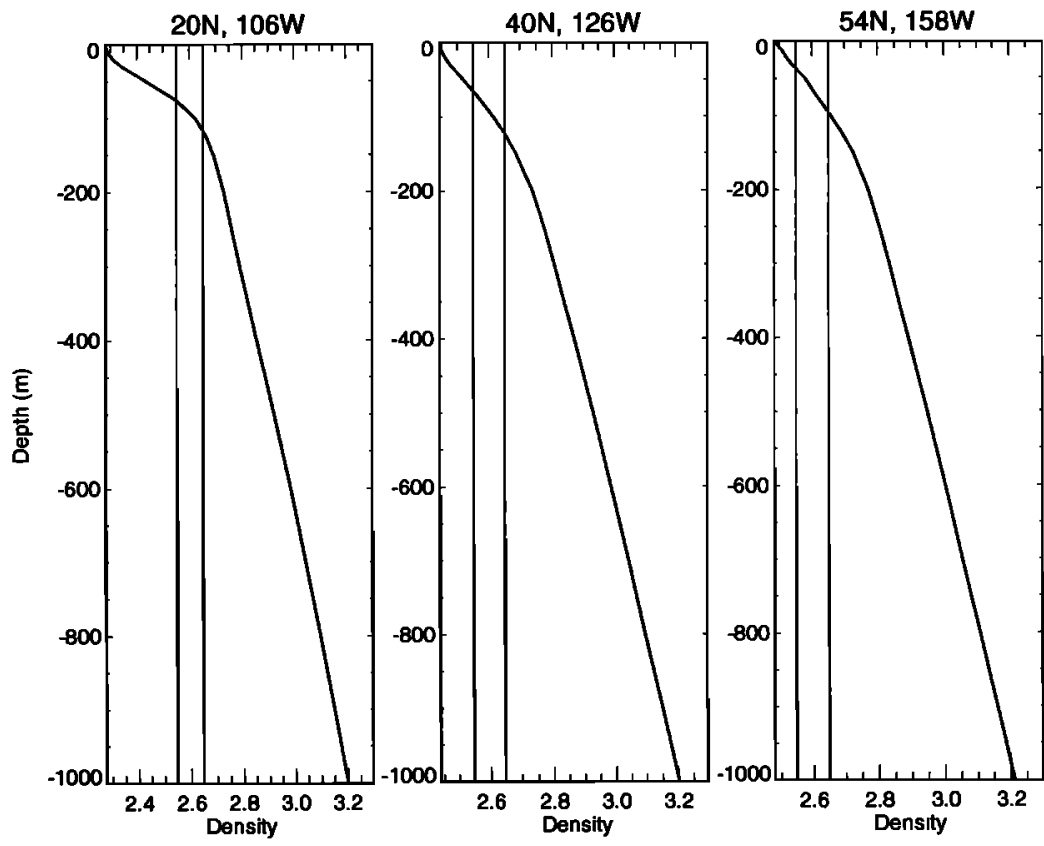

Figure 3. Density profiles from the Levitus atlas [Levitus and Boyer, 1994] at three positions near the coast. The vertical lines indicate the two choices of density in the reduced-gravity models used for estimating the phase speed of Kelvin waves (1025.5 and $1026.6 \mathrm{~kg} \mathrm{~m}^{-3}$ ). 

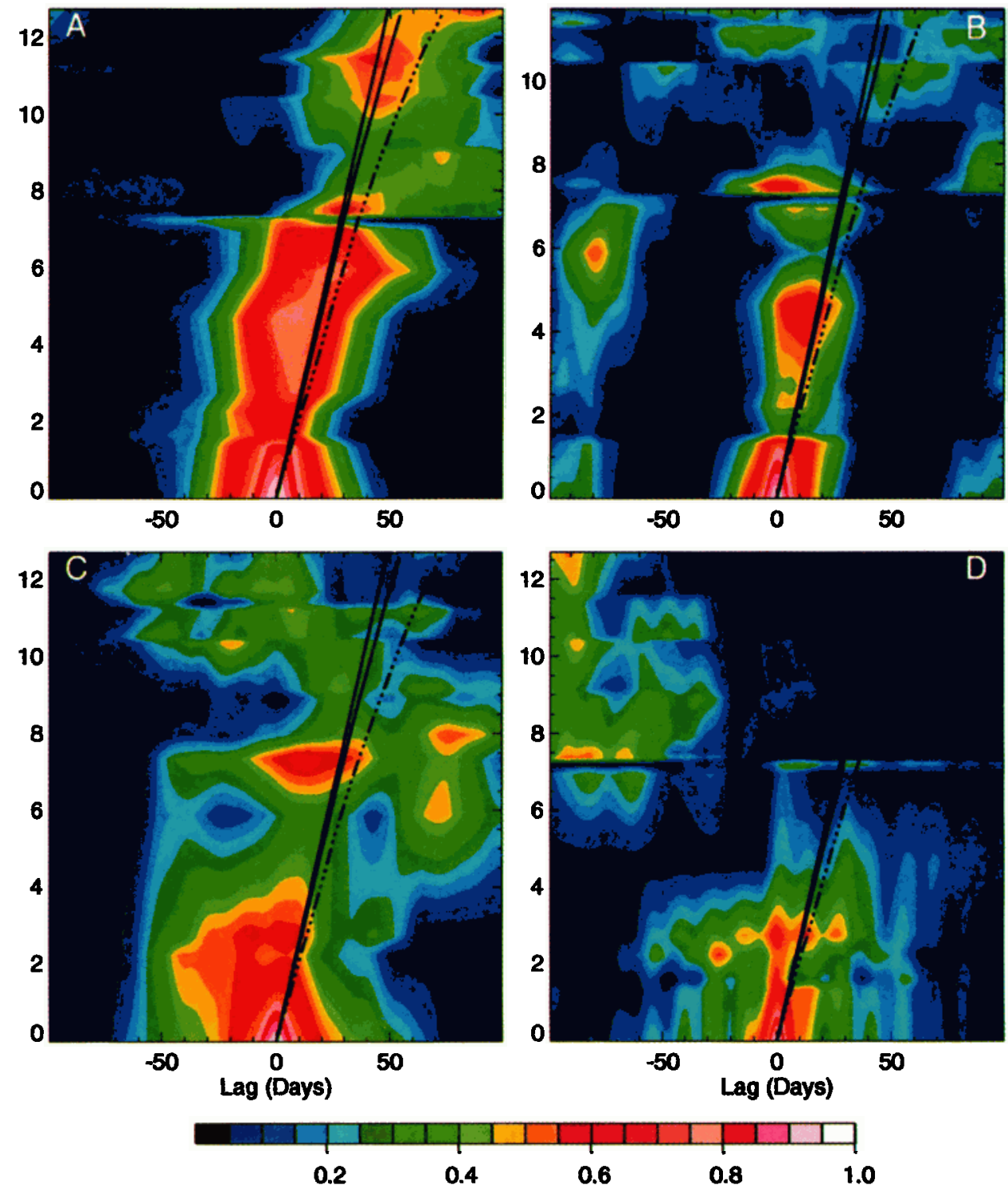

Plate 2. Lag correlations of sea level anomalies at the stations in Table 1 with the sea level anomalies at (a) Santa Cruz, Galapagos, using only mid-1982 through mid-1983 measurements; (b) Baltra, Galapagos, using only mid-1986 through mid-1987 measurements; (c) Baltra, Galapagos, using only mid-1991 through mid-1992 measurements; and (d) Baltra, Galapagos, using only mid-1985 through mid-1986 measurements. Distance from Galapagos is the vertical axis in units of $1000 \mathrm{~km}$. The straight line (farthest left) represents a speed of $3 \mathrm{~m} \mathrm{~s}^{-1}$. The theoretical propagation (middle line) is based on a pycnocline at the $1025.5 \mathrm{~kg} \mathrm{~m}^{-3}$ isopycnal, and the dash-dotted line is for the $1026.5 \mathrm{~kg} \mathrm{~m}^{-3}$ isopycnal (Figure 3). Black indicates correlation values $\leq 0$. A station was not used in these calculations if there were large data dropouts during the time of analysis.

$t_{0}, \cdots, t_{f}$. Here a Galapagos Island SLA is always used for $x_{1}$, and the other stations are, sequentially, $x_{2}$. The number of degrees of freedom for their cross correlation is estimated as $t_{f} / \tau$, where $\tau$ is the integral time of the product of the autocorrelations $R_{1}(t) R_{2}(t)$. The tropical SLAs yield the largest $\tau$ $\simeq 80$ days. The algorithm for computing the significance level is given by Sciremammano [1979, equation (16)]. The technique assumes the number of degrees of freedom (DOF) is at least five, which is somewhat inaccurate at station 6 (4.8 DOF). The estimated values for the $1982 / 1983$ event are given in Table 1. Most of the maximum correlations are near or above the $95 \%$ significance level.

The spectral phase can also be used to estimate $c$. However, this method is found to be less robust than the correlation technique used above. Wave speeds estimated from the spectral phase lag are sensitive to the presence of other signals in the data. This is demonstrated by analyzing a synthetic sea level data set that resembles the observed coastal SLA of western North America.

\subsection{Analysis of Synthetic Sea Level}

The speed of propagation in the artificial data (e.g., Figure 5 ) is determined using both correlation and spectral techniques. The first case contains no noise $(\beta=0)$. Each station is lag correlated with the first station. A speed of $200 \mathrm{~km} \mathrm{~d}^{-1}$ is obtained. The phase difference between stations at the 4-year period is then determined as in the work by Enfield and Allen [1980], which also yields $200 \mathrm{~km} \mathrm{~d}^{-1}$. This is as expected, 
Table 1. Sea Level Stations at Named Sites and Their Relation to Sea Level Variations at Santa Cruz, Galapagos Island, Ecuador, From mid-1982 to mid-1983

\begin{tabular}{|c|c|c|c|c|c|c|c|}
\hline $\begin{array}{l}\text { Station } \\
\text { Number }\end{array}$ & Location & $\begin{array}{c}\text { Distance, } \\
\mathrm{km}\end{array}$ & $\begin{array}{c}\text { Delay, } \\
\text { days }\end{array}$ & $\begin{array}{l}\text { Maximum } \\
\text { Correlations }\end{array}$ & $\begin{array}{c}\bar{c} \\
\mathrm{~m} \mathrm{~s}^{-1}\end{array}$ & $\begin{array}{c}\tau, \\
\text { days }\end{array}$ & $C_{95}$ \\
\hline 0 & Santa Cruz, Galapagos $00-45^{\circ} \mathrm{S}, 0.0-19^{\circ} \mathrm{W}$ & 0 & 01.0 & $\cdots$ & 82.5 & $\cdots$ & \\
\hline 1 & Tumaco, Columbia, $01-50^{\circ} \mathrm{N}, 078-44^{\circ} \mathrm{W}$ & 1308 & 1 & 0.88 & 15.5 & 63.7 & 0.84 \\
\hline 2 & Buenaventura, Colombia, $03-54^{\circ} \mathrm{N}, 077-06^{\circ} \mathrm{W}$ & 1600 & 1 & 0.71 & 18.9 & 46.1 & 0.72 \\
\hline 3 & Balboa, Panama, $08-58^{\circ} \mathrm{N}, 079-34^{\circ} \mathrm{W}$ & 2224 & 3 & 0.71 & 8.7 & 47.4 & 0.73 \\
\hline 4 & Quepos, Costa Rica, $09-24^{\circ} \mathrm{N}, 084-10^{\circ} \mathrm{W}$ & 2731 & 9 & 0.81 & 3.6 & 60.4 & 0.82 \\
\hline 5 & Acapulco, Mexico, $16-50^{\circ} \mathrm{N}, 099-55^{\circ} \mathrm{W}$ & 4623 & 5 & 0.82 & 10.8 & 60.0 & 0.82 \\
\hline 6 & Cabo San Lucas, Mexico, $22-53^{\circ} \mathrm{N}, 109-55,28 \mathrm{~W}$ & 5866 & 25 & 0.82 & 2.7 & 75.4 & 0.92 \\
\hline 7 & San Quintin, Mexico, $30-29^{\circ} \mathrm{N}, 115-59^{\circ} \mathrm{W}$ & 6926 & 26 & 0.69 & 3.1 & 47.0 & 0.72 \\
\hline 8 & San Diego, United States, $32-43^{\circ} \mathrm{N}, 117-10^{\circ} \mathrm{W}$ & 7199 & 5 & 0.51 & 16.7 & 46.4 & 0.72 \\
\hline 9 & Los Angeles, United States, $33-43^{\circ} \mathrm{N}, 118-16^{\circ} \mathrm{W}$ & 7350 & 29 & 0.55 & 2.9 & 29.6 & 0.58 \\
\hline 10 & Long Beach, United States, $33-47^{\circ} \mathrm{N}, 118-15^{\circ} \mathrm{W}$ & 7357 & 28 & 0.59 & 3.1 & 35.8 & 0.63 \\
\hline 11 & Rincon Island, United States, 34-21 ${ }^{\circ} \mathrm{N}, 119-26^{\circ} \mathrm{W}$ & 7483 & 29 & 0.61 & 3.0 & 32.3 & 0.60 \\
\hline 12 & San Francisco, United States, $37-48^{\circ} \mathrm{N}, 122-28^{\circ} \mathrm{W}$ & 7965 & 46 & 0.46 & 2.0 & 26.6 & 0.54 \\
\hline 13 & Astoria, Unıted States, $46-12^{\circ} \mathrm{N}, 123-46^{\circ} \mathrm{W}$ & 8905 & 72 & 0.49 & 1.4 & 19.0 & 0.46 \\
\hline 14 & Neah Bay, United States, $48-22^{\circ} \mathrm{N}, 124-37^{\circ} \mathrm{W}$ & 9153 & 72 & 0.38 & 1.5 & 10.8 & 0.37 \\
\hline 15 & Sitka, United States, $57-03^{\circ} \mathrm{N}, 135-21^{\circ} \mathrm{W}$ & 10,356 & 45 & 0.56 & 2.7 & 16.4 & 0.43 \\
\hline 16 & Juneau, United States, $58-18^{\circ} \mathrm{N}, 134-25^{\circ} \mathrm{W}$ & 10,505 & 40 & 0.54 & 3.0 & 13.4 & 0.39 \\
\hline 17 & Cordova, United States, $60-334^{\circ} \mathrm{N}, 145-45^{\circ} \mathrm{W}$ & 11,192 & 44 & 0.57 & 3.0 & 14.6 & 0.40 \\
\hline 18 & Seward, United States, $60-07^{\circ} \mathrm{N}, 149-26^{\circ} \mathrm{W}$ & 11,400 & 40 & 0.61 & 3.3 & 12.0 & 0.37 \\
\hline 19 & Kodiak Island, United States, $57-44^{\circ} \mathrm{N}, 152-31^{\circ} \mathrm{W}$ & 11,720 & 47 & 0.56 & 2.9 & 22.1 & 0.50 \\
\hline 20 & Unalaska, United States, 53-53N, $166-32^{\circ} \mathrm{W}$ & 12,728 & 88 & 0.61 & 1.7 & 20.1 & 0.47 \\
\hline
\end{tabular}

See Plate 2a. Shown are the path distance from Santa Cruz, the time lag of maximum correlation, the value of the maximum correlation, the distance-lag ratio $\bar{c}$ from Galapagos to the site, the integral time $\tau$ (see text), and the $95 \%$ significance level $C_{95}$ of the cross correlation. The other correlations were done with respect to Baltra, Ecuador, at $100-26^{\circ} \mathrm{S}, 090-17^{\circ} \mathrm{W}$.

since, in this case, the signal is not distorted by other processes. When $\beta>0$, the propagation speed estimated from the correlation method is not significantly altered, though the amplitude of the correlation decreases.

In contrast, the accuracy of the estimated speed using spectral phase differencing depends strongly on $\beta$. The average phase difference for each separation distance is obtained, and a least squares fit is made to obtain the propagation speed. This was done for 100 realizations of the noise. The standard deviation of the estimated speed (the expected error) from each ensemble study increases with $\beta$ (Figure 6). As the signalto-noise ratio decreases (increasing $\beta$ ), the spectral phase rapidly loses information from the propagating signal.

\section{Discussion}

Examining the SLA record only during ENSO events restricts the analysis to times when a large Kelvin wave is expected to be present. During other times the effects of local winds are considered to be the primary source of SL variability. Though wind effects are also present during an ENSO extreme, the SLA variation is presumed to be dominated by the remote signal, particularly during the strongest events. The propagation of the ENSO-forced coastal Kelvin wave along western North America is revealed in localized correlation studies. Generally, the correlations are found to be strongest in the tropics and decrease poleward. The 1982/1983 data show the clearest propagation pattern, which is not surprising since this is the strongest El Niño event (and hence produced the strongest Kelvin wave) in the modern record, prior to $1997 /$ 1998. It is anticipated that analysis of SLA from 1997/1998 will reveal a similar pattern. The other, weaker El Niño events yield more complex results. Correlations during the other ENSO events are not as high and are suggestive of other processes, indicating there is strong interevent variability in the progression of the coastal wave from the tropics to high lati- tudes. Interevent variations in the tropical wind anomaly were discussed by Wang [1995] and Goddard and Graham [1997]. These generate interevent differences in the Kelvin signal, as seen in Plate 1. A second source of variability is the alongshore wind component, which is affected by the position of the Aleutian Low [Ramp et al., 1997]. Understanding the mechanisms driving these interevent variations is an ongoing topic of research. Non-ENSO times lack positive correlations at positive lags in the NEP, suggesting there is no strong teleconnection from the tropics to latitudes higher than about $30^{\circ} \mathrm{N}$.

The lag correlations in Plate 2 contain abrupt variations to regions of low correlation, implying the Kelvin signal is not detected at all stations. Station 8, near San Diego, consistently demonstrates a maximum correlation at a time lag inconsistent with a tropically forced Kelvin wave. The results at San Diego are suspect, since the neighboring stations to the north and south show a correct phase relationship with a tropical signal (Table 1). Additionally, the maximum correlation at San Diego is well below the $95 \%$ confidence level. The geographical location of the San Diego station may somchow be shielding it from the Kelvin signal. The maximum correlations at the Neah Bay and Astoria stations are also out of phase with a tropical Kelvin wave. The signal near Astoria may be masked by effects of the Columbia River [Chelton and Davis, 1982].

The maximum correlations for the 1982/1983 event are usually at the $95 \%$ significance level or higher. (The significance level depends upon the determination of the timescale $\tau$. Alternate methods for estimating $\tau$ will yield different significance levels.) The generally favorable comparison to the estimated propagation adds further confidence that a Kelvin wave underlies these results, though none of the calculated speeds perfectly matches the theoretical propagation speed. However, the estimated propagation based on climatological parameters is not expected to match perfectly the observed propagation. Climatology represents a mean state that is rarely observed in 

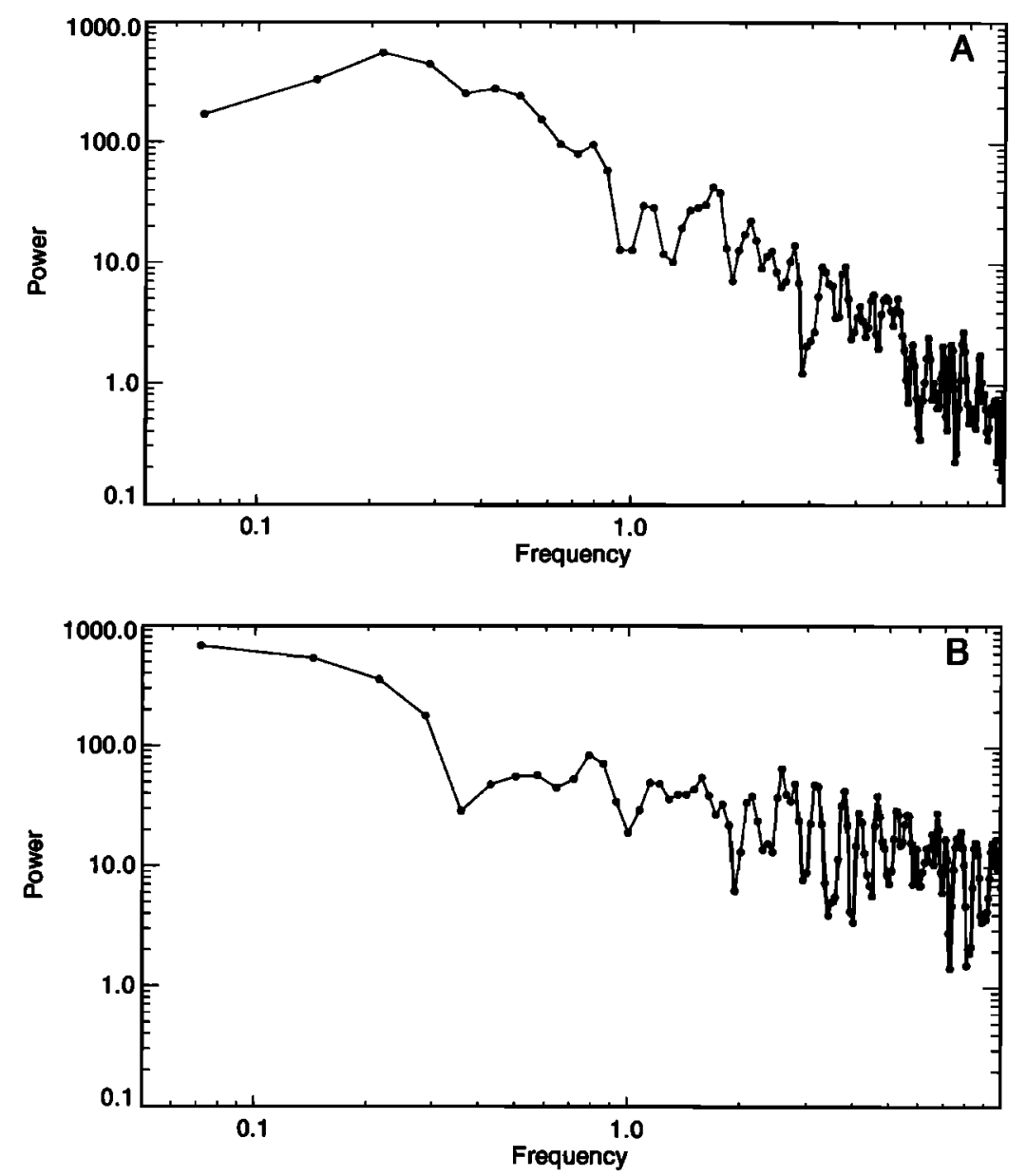

Figure 4. Power spectrum of the data in Plate 1. For frequencies less then 1 year $^{-1}$ the spectra do not possess a significant peak. (a) Santa Cruz, Galapagos, and (b) Kodiak Island, Alaska.

an instantaneous state of the ocean. An example of this would be changes due to ENSO extremes. In the El Niño phase, there is an anomalously thick mixed layer at the Pacific coast of the American continent's equatorial region. Such an anomaly yields higher propagation speed than the climatological estimate. In fact, there is a tendency for underestimation when applying the climatological propagation speeds in the tropics and subtropics in Plate 2. This may be due to our method of estimating $H$. In the tropics we find $c \geq 3 \mathrm{~m} \mathrm{~s}^{-1}$, which implies, using $\left(\rho^{-1} \Delta \rho\right) \simeq 7 \times 10^{-3}$, that $H \sim 100 \mathrm{~m}$.

An alternative approach for calculating $c$ is to solve the conventional eigenvalue problem for vertical modes that emerges in a flat-bottomed ocean in the absence of wind forcing and bottom friction when the Boussinesq approximation holds [e.g., Gill, 1982, equation (6.11.18)]. However, the horizontal resolution of the density profiles is too coarse for an accurate analysis of $c$. In fact, the internal Rossby radius (the deformation scale) is smaller than the resolution of the Levitus and Boyer [1994] data by as much as an order of magnitude in some regions. Thus the density profiles from Levitus do not reliably represent the profiles supporting the coastal waves. The stepwise density profile method above yields more robust results for $c$ than the modal formulation. The modal formulation would be more accurate if density data of an appropriate horizontal resolution became available.

The sensitivity of the spectral phase to other processes sug- gests a new explanation for the ambiguous results in previous studies: those spectral analyses of multiyear time series of SL mixed the dynamics of the tropically forced Kelvin waves with other phenomena by measuring an average spectral phase over the entire data record, yielding results that are inconsistent with both theory and numerical ocean models. An examination of synthetic data supports this hypothesis. A value of $\beta=0.08$ in the synthetic data is sufficient to give nearly a $100 \%$ expected error in the calculation of the propagation speed (Figure 6). The relative amplitude of the noise to the ENSO signal in the observational data remains uncertain (as does the analytical form of the noise). This ratio probably varies with lati-

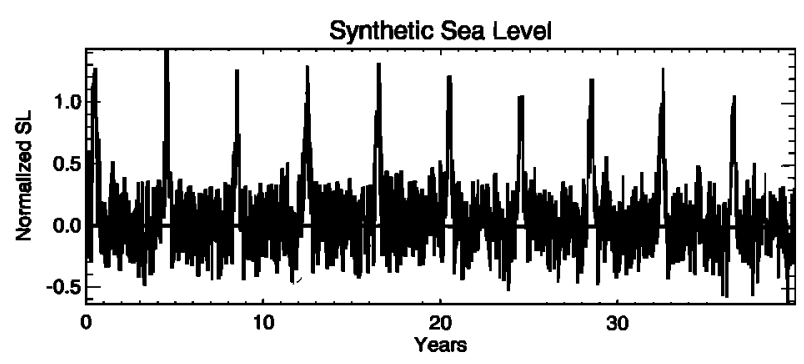

Figure 5. An example of the synthetic time series described in the text with noise strength $\beta=0.07$. 


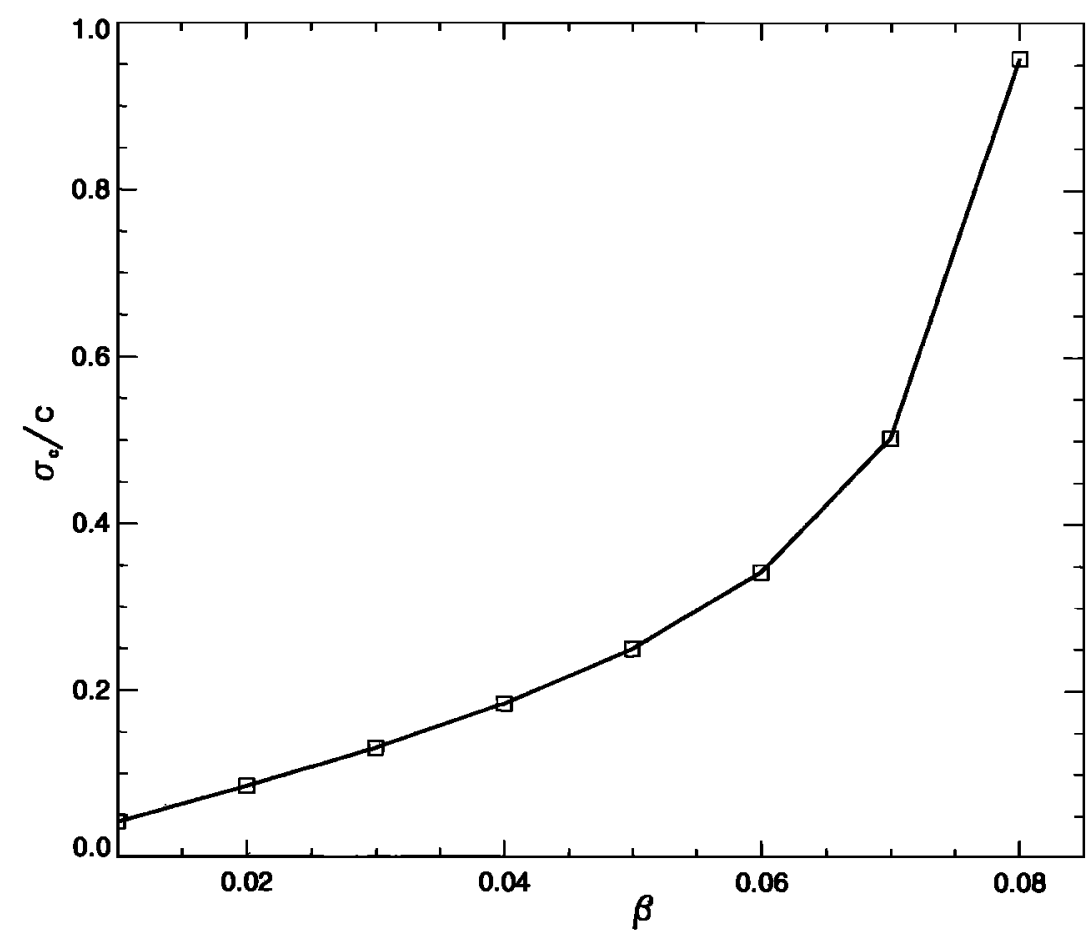

Figure 6. Expected error (standard deviation $\sigma_{c}$ ) of the estimated propagation speed between the stations of the synthetic time series normalized by the analytical speed $c$ as a function of noise strength $\beta$, based on 100 realizations for each value of $\beta$.

tude, with the tropical signal having the highest signal-to-noise ratio (low $\beta$ ) and the high latitudes having the lowest (high $\beta$ ). In the observational data there are other processes that might be altering the phase structure, such as the southward moving signal in the GOA (Plate 2c and Ramp et al. [1997]). Their influence on the spectral phase calculation is likely to be of equal strength as the red noise processes examined here.

A more accurate estimation of the relationship between SL variability and wave propagation requires an assessment of the effects of both the local winds and the remote Kelvin signal along a realistic coastline. This cannot be done analytically and requires a realistic numerical ocean model with sufficient horizontal resolution.

Acknowledgments. The Center for Ocean-Atmospheric Prediction Studies receives its base support from the Secretary of the Navy Chair awarded to J.J.O. by the Office of Naval Research, from NOAA-OGP for TOGA, and from the oceanography section of NASA headquarters. Thanks to Shikiko Nakahara for assistance with data processing and to Detlev Muller for many helpful discussions.

\section{References}

Busalacchi, A. J., and J. J. O'Brien, Interannual variability of the equatorial Pacific in the 1960 's, J. Geophys. Res., 86, 10,901-10,907, 1981.

Chelton, D. B., and R. E. Davis, Monthly mean sea-level variability along the west coast of North America, J. Phys. Oceanogr., 12, 757784,1982

Christensen, N., Jr., R. de la Paz, and G. Gutierrez, A study of subinertial waves off the west coast of Mexico, Deep Sea Res., Part A, 30, $835-850,1983$.

Clarke, A. J., The reflection of equatorial waves from oceanic boundaries, J. Phys. Oceanogr., 13, 1193-1207, 1983.

Enfield, D. B., The intraseasonal oscillation in eastern Pacific sea levels: How is it forced?, J. Phys. Oceanogr., 17, 1860-1876, 1987.
Enfield, D. B., and J. S. Allen, On the structure and dynamics of monthly mean sea level anomalies along the Pacific coast of North and South America, J. Phys. Oceanogr., 10, 557-578, 1980.

Gill, A. E., Atmosphere-Ocean Dynamics, Academic, San Diego, Calif., 1982.

Goddard, L., and N. E. Graham, El Niño in the 1990s, J. Geophys. Res., 102, 10,423-10,436, 1997.

Hurlburt, H. E., J. C. Kindle, and J. J. O'Brien, A numerical simulation of the onset of El Niño, J. Phys. Oceanogr., 6, 621-631, 1976.

Jacobs, G. A., H. E. Hurlburt, J. C. Kindle, E. J. Metzger, J. L. Mitchell, W. J. Teague, and A. J. Wallcraft, Decade-scale transPacific propagation and warming effects of an EI Niño anomaly, Nature, 370, 360-363, 1994.

Johnson, M. A., and J. J. O'Brien, The northeast Pacific Ocean response to the 1982-1983 El Niño, J. Geophys. Res., 95, 7155-7166, 1990.

Kessler, W. S., M. J. McPhaden, and K. M. Weickmann, Forcing of intraseasonal Kelvin waves in the equatorial Pacific, J. Geophys. Res., $100,10,613-10,631,1995$.

Levitus, S., and T. P. Boyer, World ocean atlas 1994: Temperature, Tech. Rep., 4, 117 pp., Natl. Environ. Satell. Data and Inf. Serv., Silver Spring, Md., 1994.

Levitus, S., and R. Gelfeld, NODC inventory of physical oceanographic profiles. Key to oceanographic records documentation, Tech. Rep., 18, Natl. Oceanogr. Data Cent., Silver Spring, Md., 1992.

Levitus, S., R. Gelfeld, T. Boyer, and D. Johnson, Results of the NODC and IOC oceanographic data archaeology and rescue projects. Key to oceanographic records documentation, Tech. Rep., 19, Natl. Oceanogr. Data Cent., Silver Spring, Md., 1994.

Lukas, R., S. P. Hayes, and K. Wyrtki, Equatorial sea level response during the 1982-1983 El Niño, J. Geophy. Res., 89, 10,425-10,430, 1984.

McCalpin, J. D., Rossby wave generation by poleward propagating Kelvin waves: The midlatitude, quasigeostrophic approximation, $J$. Phys. Oceanogr., 25, 1415-1425, 1995.

McCreary, J., Eastern tropical response to changing wind systems: With application to El Niño, J. Phys. Oceanogr., 6, 632-645, 1976.

Meyers, S. D., M. Johnson, M. Liu, J. O'Brien, and J. L. Spiesberger, Interdecadal variability in a numerical model of the northeast Pacific Ocean. 1970-1989, J. Phys. Oceanogr., 26, 2635-2652, 1996. 
Moore, D. W., Planetary-gravity waves in an equatorial ocean, Ph.D. thesis, Harvard Univ., Cambridge, Mass., 1968.

Norton, J. G., and D. R. McLain, Diagnostic patterns of seasonal and interannual temperature variation off the west coast of the United States: Local and remote large-scale atmospheric forcing, J. Geophys. Res., 99, 16,019-16,030, 1994.

Pares-Sierra, A., and J. J. O'Brien, The seasonal and interannual variability of the California current system: A numerical model, $J$. Geophys. Res., 94, 3159-3180, 1989.

Ramp, S. R., J. L. McClean, C. A. Collins, A. J. Semtner, and K. A. S. Hays, Observations and modeling of the 1991-1992 El Niño signal off central Calıfornia, J. Geophys. Res., 102, 5553-5582, 1997.

Sciremammano, F., Jr., A suggestion for the presentation of correlations and their significance levels, J. Phys. Oceanogr., 9, 1273-1276, 1979.

Spillane, M. C., D. B. Enfield, and J. S. Allen, Intraseasonal oscillations in sea level along the west coast of the Americas, J. Phys. Oceanogr., 17, 313-325, 1987.

Wang, B., Interdecadal changes in El Nin̄o onset in the last four decades, J. Clim., 8, 267-285, 1995.
Ware, D. M., and R. E. Thomson, Link between long-term variability in upwelling and fish production in the Northeast Pacific Ocean, Fish. Oceanogr., 48, 2296-2306, 1991.

Wyrtki, K., Equatorial currents in the Pacific 1950 to 1970 and their relations to the trade winds, J. Phys. Oceanogr., 4, 372-380, 1974.

A. Melsom, Norwegian Meteorological Institute, P.O. Box 43, Blindern, N-0313 Oslo, Norway. (email: arne.melsom@dnmi.no)

S. D. Meyers and G. T. Mitchum, Department of Marine Science, University of South Florida 140 7th Avenue South, St. Petersburg, FL 33701. (meyers@stommel.marine.usf.edu; mitchum@marine.usf.edu) J. J. O'Brien, Center for Ocean-Atmospheric Prediction Studies, Florida State University, Tallahassee, FL 32306. (obrien@ coaps.fsu.edu)

(Received August 27, 1997; revised April 22, 1998; accepted June 16, 1998.) 